\title{
The Impact Activity on the Quality of Life of Seniors Living in Retirement Homes
}

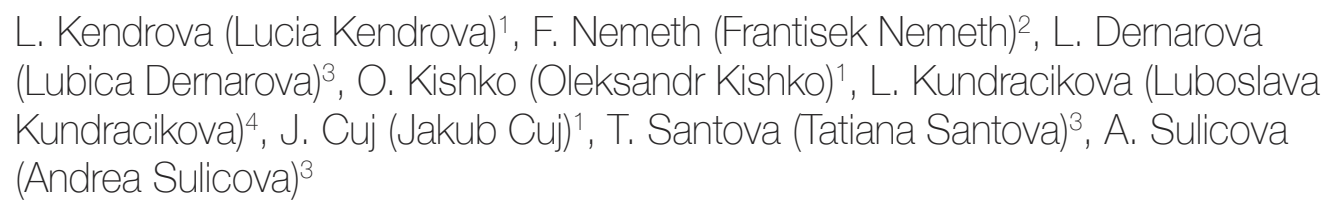

L. Kendrova (Lucia Kendrova) ${ }^{1}$, F. Nemeth (Frantisek Nemeth)², L. Dernarova (Lubica Dernarova) $^{3}$, O. Kishko (Oleksandr Kishko)1, L. Kundracikova (Luboslava

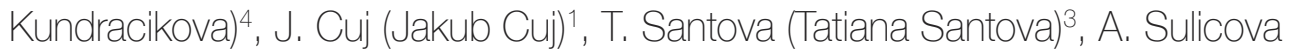
(Andrea Sulicova) ${ }^{3}$

${ }^{1}$ University of Presov in Presov, Faculty of Health Care, Department of Physiotherapy, Slovakia.

${ }^{2}$ University of Presov in Presov, Faculty of Health Care, Department of Dental Hygiene, Slovakia.

${ }^{3}$ University of Presov in Presov, Faculty of Health Care, Department of Nursing, Slovakia.

${ }^{4}$ St. Elizabeth College of Health and Social Work, Bratislava, Slovakia.

\section{E-mail address:}

Lucia.Kendrova@unipo.sk

\section{Reprint address:}

Lucia Kendrova

University of Presov in Presov

Faculty of Health Care, Department of Physiotherapy

Partizanska 1

08001 Presov

Slovakia

Source: Clinical Social Work and Health Intervention

Volume: 11

Issue: 3

Pages: $20-28$

Cited references: 50

\section{Reviewers:}

Selvaraj Subramanian

Kuala Lumpur, Malaysia

Michael Costello

University of Scranton School of Education, USA

\section{Keywords:}

Seniors, Physical activity, Quality of life, ActiGraph.

\section{Publisher:}

International Society of Applied Preventive Medicine i-gap

CSWHI 2020; 11(3): 20 - 28; DOI: 10.22359/cswhi_11_3_03 (C) Clinical Social Work and Health Intervention

Abstract:

Objective: The aim of this research to find out whether physical activity (PA) affects the quality of life (QoL) of seniors living in retirement homes.

Design: Prospective study.

Participants: The study group consisted of 47 seniors. The 
average age was 80.09 years of age ( $\mathrm{SD} \pm 6.10)$. The group included mobile and independent seniors capable of independent activity. The research was carried out in a retirement home in Sabinov.

Methods: The seniors performed the activity program in the outdoor and indoor areas of the facility. We evaluated the QoL before and after the intervention (WHOQOL-BREF and WHOQOL-OLD). PA was measured using accelerometer ActiGraph GT3X+. The intervention lasted 12 weeks.

Results: The results point to improved parameters, namely: calories and sitting. An improvement could also be seen in mild and moderate physical activity $(\mathrm{p}<0.05)$. QoL was confirmed only in the following domains: Psychological and Health satisfaction $(\mathrm{p}<0.05)$.

Conclusion: Although the evaluation of the overall QoL of seniors as a result of the activity program had negative results, we can conclude that physical activity is very important and we should not let seniors do nothing in a latent state.

\section{Introduction}

The basic component of geriatric prevention is physical activity. The low PA of seniors is the cause of many chronic disease, e.g. type 2 diabetes, obesity, diseases of the locomotive apparatus and cancer ${ }^{1,2}$. Preventive treatment of cardiovascular diseases, reduced mortality and prolonged physical and mental activity of seniors is linked to regular $\mathrm{PA}^{2}$.

According to $\mathrm{WHO}^{3}$, moderate to highly intensive activity performed per week 3 to 5 days lasting 30 to 60 minutes focuses endurance and promotes increased bone density. Adults aged 65 years and over should exercise aerobic PA with moderate intensity over a week of at least 150 minutes or a vigorous PA intensity of at least 75 minutes or a combination of PA throughout the week $^{3}$. Studies conducted in different countries show that PA could improve the QoL of older adults ${ }^{4,5,6}$.

As the world population ages, special attention needs given to health behavior of seniors people $^{7,8,9}$. PA enables seniors to reinforce their selfactivity and self-efficacy thereby ensuring a high QoL. Many studies monitor the percentage of adults and older whether it satisfies the PA recommendations for their health ${ }^{7,10,11}$. Studies suggest the importance between PA and QoL in middle-aged and older adults ${ }^{7,12,13,14}$. PA was not measured by accelerometer, but by subjective evaluation provided by the seniors themselves ${ }^{7}$. Studies suggest the importance between PA and
QoL in middle-aged and older adults ${ }^{7}$. Since PA was not measured by accelerometer, but by subjective evaluation provided by the elderly themselves, it has been confirmed that PA is often overstated $^{15,16}$. PA is usually overestimated (per day by 20 to 40 minutes) and sedentary breaks are underestimated (per day by 2 to 4 hours) 17,18,19,20.

PA and sedentary way of life are significant influential risk factors ${ }^{18,21,22}$. Objective measuring devices using body-worn sensors provide a detailed and accurate assessment of the amount of PA and sitting of seniors throughout the day ${ }^{23}$. In extensive studies, PA and sedentary breaks are often justified in terms of logistics rather than measurements ${ }^{17,23,24}$.

The aim of the study was to find out to find out whether PA affects the QoL of seniors living in retirement homes.

\section{Groups and methods}

The group consisted of 47 seniors (31 women and 16 men). The mean age was 80.09 years old $(\mathrm{SD} \pm 6.10)$. The group included mobile and independent seniors capable of independent movement. The research was carried out in a retirement home in Sabinov. The seniors performed the activity program in the outdoor and indoor areas of the facility. Before the intervention, seniors completed the following QoL questionnaires: WHOQOL - BREF and WHOQOL - OLD. The ActiGraph GT3X+ device was then assigned to the elderly to measure their PA. During the first 
week of wearing this device, respondents performed normal PA. During the weeks 2-12, PA was incorporated in the daily life of seniors, consisting of a regular 30-minute walk of moderate intensity (5 times a week) and a 10-minute exercise. Exercises were carried out in a gym and walks took place in the outdoor areas adjacent to the facility. After the intervention, the ActiGraph GT3X+ device was used on the seniors again. At the end of this period, seniors filled out the WHOQOL - BREF and WHOQOL - OLD questionnaires again. Exclusion criteria were also non-cooperation or non-consent of the patient. The research conformed to the Helsinki Declaration and was approved by the ethics committee of the treatment facility. Informed consent was signed all patients.

\section{Measurements}

To assess regular PA among our respondents as an objective way of evaluating PA, we chose a data recording and collecting method using a three-axis accelerometer, the ActiGraph GT3X+ device at the beginning and at the end of the measurement. Seniors were instructed to wear the accelerometer on their waist or wrist for 7 consecutive days. The data retained for analysis met the criterion for verifying wear time. A 60 minute break was assigned for personal hygiene ${ }^{25}$. These data were then downloaded in the ActiLife software package as follows: sitting $(<50$ pulses / minute), activity (50-1040 pulses / minute) and moderate to strong PA (MVPA; $\geq 1041$ pulses / minute $)^{26,27}$. Every minute of wear was classified as sitting, light or moderate PA. The estimated average daily minutes spent in each intensity category were calculated by dividing the number of minutes spent in each category by the total num- ber of valid days of wear per participant ${ }^{27}$.

The WHOQOL-OLD questionnaire has 24 questions divided into six domains: the functioning of the senses; independence; fulfillment; social engagement; death and dying; close relationships. These domains are calculated with a gross score, which is the average of the 4 items for each domain $^{28}$.

The WHOQOL-BREF questionnaire has of 26 questions. They are evaluated separately, first and second questions. They concerned general perception of QoL in relation to Health Satisfaction (Q1, Q2). The remaining 24 questions were to evaluate four aspects of QoL (Physical health - 7 questions; Psychological - 6 questions; Social relationships - 3 questions; Environment - 8 questions $)^{4}$. Seniors marked the answer on a scale of 1 to 5 points. QoL in each domain was calculated by key as an average value. Higher scores indicate better QoL ${ }^{4,28,29,30}$.

\section{Statistical Analysis}

The evaluation was made by comparing before and after the 12-week intervention. We used descriptive statistics to process the data. The results from the ActiGraph GT3X+ and the QoL were evaluated using a paired t-test. The statistical analysis was performed using the IBM SPSS 19 software. Data are presented as mean \pm 1 SD or as $\%$ percentages. The level of statistical significance was set at $\mathrm{p}<0.05$.

\section{Results}

Our group consisted of 47 seniors (31 women and 16 men). The average age was 80.09 years old $(\mathrm{SD} \pm 6.10)$. The results obtained with ActiGraph GT3X+ evaluated by paired t-test were recorded in Table 1.

Table 1 Selected ActiGraph GT3X+ parameters

\begin{tabular}{|l|l|l|c|c|}
\hline Parameters ActiGraph GT3X + & Treatment & Average (SD) & $\mathbf{t}$ & P value \\
\hline \multirow{2}{*}{ kcals } & Before & $591.46 \pm 526.26$ & -2.52 & $\mathbf{0 . 0 1 5}$ \\
\cline { 2 - 4 } & After & $757.23 \pm 754.15$ & & \\
\hline \multirow{2}{*}{ METs } & Before & $1.01 \pm 0.02$ & 1.87 & 0.068 \\
\cline { 2 - 3 } & After & $1.00 \pm 0.00$ & & \\
\hline \multirow{2}{*}{$\begin{array}{l}\text { Total time spent } \\
\text { inactivity (min) }\end{array}$} & Before & $8269.49 \pm 921.44$ & \multirow{2}{*}{3.04} & $\mathbf{0 . 0 0 4}$ \\
\cline { 2 - 3 } Number of breaks & After & $7933.12 \pm 973.10$ & & 0.344 \\
\cline { 2 - 3 } & Before & $118.02 \pm 25.60$ & 0.95 & \\
\cline { 2 - 3 } & After & $113.12 \pm 33.46$ & & \\
\hline
\end{tabular}




\begin{tabular}{|c|c|c|c|c|}
\hline \multirow{2}{*}{$\begin{array}{l}\text { Total time spent } \\
\text { on breaks (min) }\end{array}$} & Before & $1952.43 \pm 897.27$ & \multirow[t]{2}{*}{2.24} & \multirow[t]{2}{*}{0.030} \\
\hline & After & $1725.00 \pm 909.41$ & & \\
\hline \multirow{2}{*}{$\begin{array}{l}\text { Average time of } \\
\text { sedentary breaks ( } \mathrm{min})\end{array}$} & Before & $17.23 \pm 9.30$ & \multirow[t]{2}{*}{2.41} & \multirow[t]{2}{*}{0.020} \\
\hline & After & $14.93 \pm 7.38$ & & \\
\hline \multirow{2}{*}{$\begin{array}{l}\text { Daily average of } \\
\text { sedentary breaks (min) }\end{array}$} & Before & $246.22 \pm 113.84$ & \multirow[t]{2}{*}{2.41} & \multirow[t]{2}{*}{0.012} \\
\hline & After & $215.62 \pm 113.68$ & & \\
\hline \multirow[t]{2}{*}{ Light activity (min) } & Before & $805.19 \pm 439.03$ & \multirow[t]{2}{*}{2.32} & \multirow[t]{2}{*}{0.024} \\
\hline & After & $911.98 \pm 439.03$ & & \\
\hline \multirow[t]{2}{*}{ Moderate activity (min) } & Before & $105.74 \pm 124.55$ & \multirow[t]{2}{*}{1.56} & \multirow[t]{2}{*}{0.125} \\
\hline & After & $132.81 \pm 147.40$ & & \\
\hline \multirow[t]{2}{*}{ Medium activity (min) } & Before & $10.19 \pm 14.88$ & \multirow[t]{2}{*}{1.99} & \multirow[t]{2}{*}{0.052} \\
\hline & After & $22.23 \pm 47.37$ & & \\
\hline \multirow[t]{2}{*}{ Percentage of MVPA time } & Before & $0.09 \pm 0.16$ & \multirow[t]{2}{*}{2.22} & \multirow[t]{2}{*}{0.031} \\
\hline & After & $0.22 \pm 0.47$ & & \\
\hline \multirow[t]{2}{*}{ Average time in MVPA (min) } & Before & $1.27 \pm 1.86$ & \multirow[t]{2}{*}{2.03} & \multirow[t]{2}{*}{0.048} \\
\hline & After & $2.81 \pm 5.93$ & & \\
\hline \multirow{2}{*}{$\begin{array}{l}\text { The number of steps in } \\
\text { the activity }\end{array}$} & Before & $11257.04 \pm 11913.64$ & \multirow[t]{2}{*}{1.35} & \multirow[t]{2}{*}{0.182} \\
\hline & After & $13024.15 \pm 12,657.94 \mathrm{i}$ & & \\
\hline
\end{tabular}

Seniors had fewer breaks during the day, as evidenced by statistical significance $(\mathrm{p}<0.05)$. Improved parameters were: calories; total inactivity time; total sedentary time; average sedentary time; daily sedentary average. There was no improvement in mild and moderate activity and activity steps $(\mathrm{p}>0.05)$. In our group, there was an improvement in light and moderate PA during the 12-week intervention $(\mathrm{p}<0.05)$.

Table 2 Evaluation of OoL using the WHOOQOL-OLD questionnaire

\begin{tabular}{|c|c|c|c|c|}
\hline $\begin{array}{l}\text { WHOQOL-OLD } \\
\text { questionnaire domains }\end{array}$ & Treatment & Average (SD) & $t$ & P value \\
\hline \multirow[t]{2}{*}{ Sensory abilities } & Before & $3.42 \pm 0.67$ & \multirow[t]{2}{*}{-1.45} & \multirow[t]{2}{*}{0.153} \\
\hline & After & $3.57 \pm 0.76$ & & \\
\hline \multirow[t]{2}{*}{ Autonomy } & Before & $3.16 \pm 0.59$ & \multirow[t]{2}{*}{-0.21} & \multirow[t]{2}{*}{0.832} \\
\hline & After & $3.18 \pm 0.67$ & & \\
\hline \multirow{2}{*}{$\begin{array}{l}\text { Past, present and future } \\
\text { activities }\end{array}$} & Before & $3.40 \pm 0.50$ & \multirow[t]{2}{*}{-0.43} & \multirow[t]{2}{*}{0.670} \\
\hline & After & $3.45 \pm 0.70$ & & \\
\hline \multirow[t]{2}{*}{ Social participation } & Before & $3.55 \pm 0.68$ & \multirow[t]{2}{*}{0.87} & \multirow[t]{2}{*}{0.389} \\
\hline & After & $3.42 \pm 0.90$ & & \\
\hline \multirow[t]{2}{*}{ Death and dying } & Before & $4.26 \pm 0.99$ & \multirow[t]{2}{*}{0.87} & \multirow[t]{2}{*}{0.390} \\
\hline & After & $4.10 \pm 0.96$ & & \\
\hline \multirow[t]{2}{*}{ Intimacy } & Before & $3.80 \pm 0.67$ & \multirow[t]{2}{*}{-0.40} & \multirow[t]{2}{*}{0.688} \\
\hline & After & $3.87 \pm 0.92$ & & \\
\hline
\end{tabular}

The QoL evaluation of seniors using the WHOQOL-OLD questionnaire shows only a minimal improvement (Table 2), as evidenced by statistical significance that has not been confirmed $(\mathrm{p}>0.05)$. 
Table 3 OOL Assessment using the WHOQOL-BREF questionnaire

\begin{tabular}{|l|l|l|l|c|}
\hline WHOQOL-BREF domains & Treatment & Average (SD) & $\mathbf{t}$ & P value \\
\hline Physical health & Before & $3.44 \pm 0.42$ & 0.51 & 0.610 \\
& After & $3.48 \pm 0.52$ & & \\
\hline Psychological & Before & $3.48 \pm 0.47$ & -0.20 & $\mathbf{0 . 0 5 0}$ \\
& After & $3.63 \pm 0.53$ & & \\
\hline Social relationship & Before & $3.51 \pm 0.45$ & 0.84 & 0.407 \\
& After & $3.57 \pm 0.48$ & & \\
\hline Environmental & Before & $3.78 \pm 0.42$ & 0.23 & 0.822 \\
& After & $3.76 \pm 0.50$ & & \\
\hline Q1 - Quality of life & Before & $3.62 \pm 0.53$ & 0.18 & 0.855 \\
& After & $3.59 \pm 0.68$ & & \\
\hline Q2 - Satisfaction & Before & $3.17 \pm 0.87$ & -2.01 & $\mathbf{0 . 0 5 0}$ \\
with health & After & $3.42 \pm 0.74$ & & \\
\hline
\end{tabular}

We also measured the QoL of seniors using the WHOQOL-BREF questionnaire. Again, the results point to minimal improvements in Physical Health, Social Relations, Environmental and QoL domains. Statistical significance was confirmed in the Psychological and Q2 - Health Satisfaction domains $(\mathrm{p}<0.05)$ (Table 3).

This result can be attributed to associated health problems after PA, which could lead them to the belief that their independence had deteriorated and fatigue could lead to reduced time for social activities, i.e. social involvement and close relationships.

\section{Discussion}

The aim of the study was to find out to find out whether PA affects the QoL of seniors living in retirement homes. The results obtained with the ActiGraph GT3X+ monitoring accelerometer indicate that seniors had fewer breaks during the day post-intervention, as demonstrated by statistical significance $(\mathrm{p}<0.05)$. Improved parameters included: calories; total inactivity time; total sedentary time; average sedentary time; daily sedentary average. In our group, there was an improvement in light and moderate PA during the 12 -week intervention $(\mathrm{p}<0.05)$. However, we observed only mild and moderate activity in the seniors. Seniors had the ActiGraph GT3X+ monitoring accelerometer attached on the waist or wrist. The Korpan et al. ${ }^{31}$ study (2015) points out that the accuracy of step counting using the accelerometer can be influence by walking speed, device location, and the choice of analysis algorithm. In the study, they evaluated the accuracy of the ActiGraph GT3X+ step counting in relation to the placement algorithm and device analysis seniors who used walking aids, but also with- out aids. Participants (81.5 years of age) underwent a timed 100 - meter walk with 5 accelerometer GT3X+ monitors (hips, ankles, lumbar spine $)^{31}$. They found that GT3X+ in the ankle area led to the most accurate step counting in older adults. Barriers can also play a role in lower PA due to problems such as fear of falling, especially among older women ${ }^{31,32}$.

Kerr et al. ${ }^{33}$ (2011) reports that older adults living in retirement homes reported better health status and less sedentary time at their discretion. Kerr et al..$^{33}$ (2011) investigated built-in environmental elements and used objective measurements of the level of PA in seniors living in senior homes. There were supporting external features associated with residents who achieved a higher level of moderate to intense PA, but no effect was observed on the internal elements of the building. The study focused on exercise in the building ${ }^{33}$.

In their research, Rosenberg et al. ${ }^{34}$ (2013) investigated the barriers to walking of older people with disabilities. The elderly reported the most common obstacle that they did not feel very well 
visible to drivers and they felt fast traffic. Obstacles were also sunlight, heat or rain. Also, uphill walking and stairs that are a barrier for them to walk ${ }^{34}$.

We also measured the QoL of seniors using the WHOQOL-BREF and WHOQOL-OLD questionnaire. The assessment of the QoL of seniors by the WHOQOL-OLD questionnaire shows only a minimal improvement ( $p>0.005$ ). Statistical significance was confirmed in the WHOQOL-BREF questionnaire in the Psychological and Health Satisfaction domains - Q2 (p $<0.05)$. This result can be attributed to associated health problems after PA, which could lead them to believe that their independence has deteriorated, and due to fatigue there was a lack of time for social activities, i.e. social involvement and close relationships.

The Nawrocka et al. ${ }^{35}$ (2019) study found that the QoL in the domain of social relationships is significantly related to the level of PA. They found that PA women had a slight improvement in QoL scores, regardless of the area as women who were underactive ${ }^{35}$. Many studies have seen the positive impact of PA on the QoL ${ }^{35,36,37,38}$. In his study, Vagetti et al. ${ }^{14}$ (2015) detect improvement in the ten domains of QoL connected with higher frequency moderate to vigorous PA even at a weekly physical activity ${ }^{14}$. A study conducted with the Polish population of Puciato et al. ${ }^{39}$ (2018) evaluated the QoL using the WHOQOLBREF questionnaire, found that by increasing the respondents" PA there was improved overall QoL $^{39,35}$. In their study, they evaluated PA using an international questionnaire on PA (IPAQ) ${ }^{39}$ while our study focused on evaluating PA using an accelerometer.

The purpose of the Awick et al..$^{40}$ (2017) examined how changes in PA and psychological distress affected changes in QoL during a sixmonth exercise for older adults ${ }^{40}$. Their study is the first to investigate the effect of psychological suffering in relation to physical therapy. They noted a higher increase in moderate and intense PA during the research resulted in a decrease in psychological distress and positively affected the QoL ${ }^{40}$.

Vagetti et al.$^{41}$ found one connection in sensory ability with $\mathrm{PA}^{41}$. In many studies, there are conflicting results in connection with PA and many domains QoL.42. Different frequencies and intensities of PA effect factors on QoL. It depends on the intensity of PA and on the method of evaluation of PA and QoL about what methodology is involved, whether subjective or objective measurement ${ }^{42}$. For seniors, a movement program is recommended that can improve the QoL: aerobic; anaerobic; strength training; stretching exercises; leisure activities; etc ${ }^{41}$.

Light PA was associated with the domains SF-36: general health; vitality; social function; mental health ${ }^{43}$. Another study was associated with a $40 \%$ lower probability of low scores in the physical and mental domains of HRQoL ${ }^{41,43,44}$.

The Varejão et $a l .{ }^{45}$ study (2007) in which they examined a program with low PA did not find a significant improvement in the $\mathrm{QoL}^{45}$. A previous long-term study showed that moderate PA practice predicted improvement in QoL functional capacity 46. Patients who are active and improving their physical abilities are better prepared to do any work in everyday life that, on the other hand, can promote this QoL domain ${ }^{41,47}$.

\section{Conclusion}

Europe's aging population is probably the greatest medical and socio-political challenge of the coming years. By 2050, seniors aged 60-79 are expected to account for a quarter of the EU population ${ }^{48,49}$. Regular PA has beneficial importance for seniors. It is a medicine used to prevent and treat aging-related diseases and diseases such as: hypertension; obesity; hypercholesterolemia; diabetes and osteoporosis ${ }^{2,48,50}$. PA programs developed on the basis of WHO recommendations have the potential to improve the functional capacity and QoL of seniors. The results of our studies suggest although the evaluation of the overall QoL of seniors as a result of the activity program had negative results, we can conclude that PA is very important and we should not let seniors do nothing in a latent state.

The study was supported by the project KEGA \# 009PU-4/2018 Evaluation of physical activity of seniors as a basis for improving forms of education in the field of active aging.

\section{Declaration of interest}

The authors declare that they have no conflict of interest. 


\section{References:}

1. SUMIC A, MICHAEL U, CARLSON N, HOWIESON D, KAYE J (2007) Physical activity and the risk of dementia in oldest old. $\mathrm{J}$ Aging health, 19(2):242-59.

2. SYGIT K (2015) Fundamental Significance of Physical Activity for Seniors Health. Central. European Journal of Sport Sciences and Medicine, 12(4), 53-59.

3. WORLD HEALTH ORGANIZATION (2010) Global recommendations on physical activity for health. [cited 2019 Dec. 28]. Available from: https://apps.who.int/iris/bitstream/handle/10665/44399/9789241599979_ eng.pdf;jsessionid=20FE45BEA50E9AC70 B0C7AF6E2499F4B? sequence $=1$.

4. KRZEPOTA J, BIERNAT E, FLORKIEWICZ B (2015) The relationship between levels of physical activity and quality of life among students of the university of the third age. Cent Eur J Public Health 2015; 23 (4): 335-33.

5. KU PW, MCKENNA J, FOX KR (2007) Dimensions of subjective well-being and effects of physical activity in Chinese older adults. J Aging Phys Act. 2007 Oct;15(4):382-97.27.

6. ACREE LS, LONGFORS J, FJELDSTAD AS et al. (2006) Physical activity is related to quality of life in older adults. Health Qual Life Outcomes. 2006 Jun 30; 4:37.

7. NAWROCKA A, MYNARSKI W (2017) Objective Assessment of Adherence to Global Recommendations on Physical Activity for Health in Relation to Spirometric Values in Nonsmoker Women Aged 60-75 Years. J. Aging Phys. Act. 2017, 25, 123-127.

8. PATERSON DH, WARBURTON DE (2010) Physical activity and functional limitations in older adults: A systematic review related to Canada's Physical Activity Guidelines. Int. J. Behave. Nutr. Phys. Act. 2010, 7, 38.

9. MCAULEY E, KONOPACK JF, MORRIS KS, MOTL RW et al. (2006) Physical activity and functional limitations in older women: Influence of self-efficacy. J. Gerontol. B Psychol. Sci. Soc. Sci. 2006, 61, P270P277.

10. THRALLS KJ, LEVY SS (2018) The Association Between Self-Reported Adherence to Physical Activity Recommendations and Criteria for Maintaining Physical Independence of Older Adults. J. Aging Phys. Act. 2018, 26, 171-176.

11. LUZAK A, HEIER M, THORAND B, LAXY M et al. (2017) Physical activity levels, duration pattern and adherence to $\mathrm{WHO}$ recommendations in German adults. PLoS ONE 2017, 12, e0172503.

12. PUCIATO D, BORYSIUK Z, ROZPARA M (2017) Quality of life and physical activity in an older working-age population. Clin. Interv. Aging 2017, 12, 1627-1634.

13. HAIDER S, LUGER E, KAPAN A, TITZE S et al. (2016) Associations between daily physical activity, handgrip strength, muscle mass, physical performance and quality of life in prefrail and frail community-dwelling older adults. Qual. Life Res. 2016, 25, 31293138.

14. VAGETTI GC, BARBOSA FILHO VC, MOREIRA NB, de OLIVEIRA $\mathrm{V}$ et al. (2015) The Association Between Physical Activity and Quality of Life Domains among Older Women. J. Aging Phys. Act. 2015, 23, 524-533.

15. HAGSTROMER M, AINSWORTH BE, OJA P, SJOSTROM M et al. (2010) Comparison of a subjective and an objective measure of physical activity in a population sample. $\mathrm{J}$. Phys. Act. Health 2010, 7, 541-550.

16. WICK K, FAUDE O, SCHWAGER S, ZAHNER L, DONATH L (2016) Deviation between self-reported and measured occupational physical activity levels in office employees: Effects of age and body composition. Int. Arch. Occup. Environ. Health 2016, 89, 575-582.

17. DALL PM, COULTER EH, FITZSIMONS CF, SKELTON DA, CHASTIN S, SENIORS USP Team (2017) Taxonomy of Self-reported Sedentary Behavior Tools (TASST) framework for development, comparison and evaluation of self-report tools: content analysis and systematic review. BMJ Open, 7(4), e013844.

18. DALL PM, SKELTON DA, DONTJE ML, COULTER EH et al (2018) Chastin Characteristics of a protocol to collect objective physical activity/sedentary behavior data in a large study: Seniors USP (understanding sedentary patterns) J Meas Phys Behav. 1(1): 26-31. 
19. TROIANO RP, MCCLAIN JJ, BRYCHTA RJ, CHEN KY (2014) Evolution of accelerometer methods for physical activity research. British Journal of Sports Medicine, 48, 10191023.

20. SCHALLER A, RUDOLF K, DEJONGHE L, GRIEBEN C, FROBOESE I (2016) Influencing factors on the overestimation of selfreported physical activity: A cross-sectional analysis of low back pain patients and healthy controls. BioMed Research International, 2016, 1-11.

21. BISWAS A, OH PI, FAULKNER GE, BAJAJ RR et al. (2015) Sedentary time and its association with risk for disease incidence, mortality, and hospitalization in adults: a systematic review and meta-analysis. Annals of Internal Medicine, 162, 12332.

22. EKELUND U, STEENE-JOHANNESSEN J, BROWN WJ, FAGERLAND MW et al. (2016) Does physical activity attenuate, or even eliminate, the detrimental association of sitting time with mortality? A harmonised meta-analysis of data from more than $1 \mathrm{mil}$ lion men and women. Lancet, 388(10051), 1302-1310.

23. WIJNDAELE K, WESTGATE K, STEPHENS SK, BLAIR SN et al. (2015) Utilization and harmonization of adult accelerometer data: Review and expert consensus. Medicine \& Science in Sports \& Exercise, 47(10), 2129-2139.

24. HEALY GN, CLARK BK, WINKLER EAH, GARDINER PA et al. (2011) Measurement of adults sedentary time in population-based studies. American Journal of Preventive Medicine, 41(2), 216-227.

25. TROIANO RP, BERRIGAN D, DODD KW, MASSE LC, TILERT T, McDOWELL M. (2008) Physical activity in the United States measured by accelerometer. Med Sci Sports Exerc. 2008;40(1):181-188.

26. COPELAND JL, ESLIGER DW (2009) Accelerometer Assessment of Physical Activity in Active, Healthy Older Adults. J Aging Phys Act. 2009;17(1):17-30.

27. GOTHE NP, EHLERS DK, SALERNO EA, FANNING J, KRAMER AF, MCAULEY E (2019) Physical Activity, Sleep and Quality of Life in Older Adults: Influence of Physical,
Mental and Social Well-being. Behav Sleep Med. 2019; 12:1-12.

28. GURKOVA E. (2011) Evaluation of quality of life. For clinical practice and nursing research. Published by Grada Publish. ISBN 987-80-247-3625-9 p. 213.

29. WOLOWICKA L, JARACZ K. (2001) Polish version of WHOQOL - WHOQOL 100 and WHOQOL-BREF. In: Wolowicka L, editor. Quality of life in medical sciences. Department of University Publications of the Medical Academy Karol Marcinkowski; 2001. p. 231-38.

30. PUSZCZALOWSKA-LIZIS E, FLAK K, BISKUP M, ZAK M (2020) Physical Activity of Women After Radical Unilateral Mastectomy and Its Impact on Overall Quality of Life. Cancer Control. 2020; 27(1)

31. KORPAN SM, SCHAFER JL, WILSON KC, WEBBER SC. (2015) Effect of ActiGraph GT3X+ Position and Algorithm Choice on Step Count Accuracy in Older Adults. J Aging Phys Act. 2015 Jul;23(3):377-82.

32. WALSH JM, PRESSMAN AM, CAULEY JA, BROWNER WS (2001) Predictors of physical activity in community-dwelling elderly white women. Journal of General Internal Medicine, 16, 721-727.

33. KERR J, CARLSON JA, SALLIS JF, ROSENBERG D, LEAK CR et al. (2011) Assessing health-related resources in senior living residences. Journal of Aging Studies, 25(3), 206-214.

34. ROSENBERG DE, HUANG DL, SIMONOVICH SD, BELZA B (2013) Outdoor built environment barriers and facilitators to activity among midlife and older adults with mobility disabilities. The Gerontologist, 53(2), 268-279.

35. NAWROCKA A, POLECHONSKI J, GARBACIAK W, MYNARSKI W (2019) Functional Fitness and Quality of Life among Women over 60 Years of Age Depending on Their Level of Objectively Measured Physical Activity Int J Environ Res Public Health. 2019; 16(6): 972.

36. DE CARVALHO ED, VALADARES AL, da COSTA-PAIVA LH, PEDRO AO et al. (2010) Physical activity and quality of life in women aged 60 or older: Associated factors. Rev. Bras. Ginecol. Obstet. 2010, 32, 433-440. 
37. DA FONTE E, FEITOSA PH, de OLIVEIRA NETO LT, de ARAUJO CL et al. (2016) Effects of a physical activity program on the quality of life among elderly people in Brazil. J. Family Med. Prim. Care 2016, 5, 139-142 38. OMOROU YA, ERPELDING ML, ESCALON H, VUILLEMIN A (2013) Contribution of taking part in sport to the association between physical activity and quality of life. Qual. Life Res. 2013, 22, 2021-2029.

39. PUCIATO D, ROZPARA M, BORYSIUK Z (2018) Physical Activity as a Determinant of Quality of Life in Working-Age People in Wroclaw, Poland. Int. J. Environ. Res. Public Health 2018, 15.

40. AWICK EA, EHLERS DK, AGUINAGA S, DAUGHERTY AM et al. (2017) Effects of a randomized exercise trial on physical activity, psychological distress and quality of life in older adults. Gen Hosp Psychiatry. 2017 49:44-50.

41. VAGETTI GC, FILHO VCB, MOREIRA NB, DE OLIVEIRA V et al. (2014) Association between physical activity and quality of life inthe elderly: a systematic review, 20002012. Brazilian Journal of Psychiatry. 2014;36:76-88

42. COURNEYA KS, TAMBURRINI AL, WOOLCOTT CG, MCNEELY ML et al. (2011) The Alberta Physical Activity and Breast Cancer Prevention Trial: quality of life outcomes. Prev Med. 2011; 52: 26-32.

43. GUALLAR-CASTILLON P, PERALTA PS, RAMON J, LOPEZ E, METODO SUY (2004) Physical activity and quality of life of the elderly population in Spain. Med Clin. 2004; 123: 606-10.
44. EKWALL A, LINDBERG A, MAGNUSSON M. (2009) Dizzy - why not take a walk? Low level physical activity improves quality of life. Gerontology. 2009; 55: 652-9.

45. VAREJ RV, DANTAS EHM, MATSUDO SM (2007) Comparison of the effects of stretching and flexing, both passive, on the levels of flexibility, functional capacity and quality of life of the elderly. R Bras Ci Mov. 2007; 15: 87-95.

46. WANG L, LARSON EB, BOWEN JD, van BELLE G (2006) Performance-based physical function and future dementia in older people. Arch Intern Med. 2006; 166: 111520.

47. MCAULEY E, DOERKSEN SE, MORRIS KS, MOTL RW, HU L, WOJCICKI TR et al. (2008) Pathways from physical activity to quality of life in older women. Ann Behav Med. 2008; 36: 13-20.

48. GEBSKA-KUCZEROWSKA A (2002) Assessment of the relationship between activity and health in the elderly. Przegl. Epidemiol. 2002; 56: 471-477.

49. KOSTKA T, DRYGAS W, JEGIER A, ZANIEWICZ D (2009) Aerobic and anaerobic power in relation to age and physical activity in men. Int. J. Sports Med. 2009; 30: 225230.

50. POLAK A, PARZYCH K, KEDZIORA-KORNATOWSKA K (2007) Cognitive and practical dimension of gerontology - an interdisciplinary science about aging and old age. Polish Gerontology. 2007; 15: 51-53 